\title{
Anomalous thickening in the roots of Cycas Seemanni, Al. Braun.
}

\author{
BY \\ W. H. GREGG, B.A. (DUBLIN), \\ Surgeon-Major, Bengal Army. \\ With Plate VI.
}

WHILE working in the Jodrell Laboratory, Kew, under the direction of Dr. Scott, and with material which Professor Bower kindly placed at my disposal, I found some abnormal thickening in the roots of Cycas Seemanni which does not appear to have been previously observed. Abnormal thickening in the stems of Cycas, Dioon, Zamia, and Encephalartos, has been well worked out by Mettenius and others ${ }^{1}$. The abnormality consists in the appearance of successively renewed zones of cambium outside the normal ring-each of these in turn continues its activity for a limited period, and then passes over into permanent tissue, while the process of thickening is carried on by a new zone appearing nearer the periphery of the stem. In the case of Cycas there is a further abnormal process consisting in the relatively late appearance of distinct cortical bundles-each of which undergoes a certain amount of thickening by means of a cambial ring of its own. As regards the roots of the Cycads our knowledge is far less complete. The researches of Mettenius have made us fully acquainted with the development

G. Mettenius, Beiträge zar Anatomie der Cycadeen, 1860. De Bary, Comparative Anatomy of the Vegetative Organs of the Phanerogams and Ferns, Eng. ecl., I 884.

[ Annals of Botany, Vol, L. No. I. August 1887.] 
of the primary structure, and of the normal products of thickening, in the roots of Cycas revoluta, and also in species of Dioon, Encephalartos, and Zamia. The mode of development which he describes essentially agrees with that of the roots of the Conifers; the case of the diarch root of Cycas revoluta, which he describes very fully, agreeing for example with such a root as that of Taxus. The subsequent occurrence of abnormal growth is mentioned by him in the following words (1. c. pp. 598-9): 'Mit dem höheren Alter der Wurzel erlischt endlich die Thätigkeit der Cambiumschichte, und beginnt gerade wie in dem Stamm ausserhalb des Bastes die Ausbildung einer zweiten, und schreitet das weitere Wachsthum in voller Uebereinstimmung mit dem des Stamm's fort.'

No further details however are furnished on this part of the subject, nor have later investigators, so far as I have been able to ascertain, added anything to our knowledge of the point in question. The writer who in recent times has dealt most fully with the roots of Cycadeae is Reinke; to him is due our knowledge of several points of interest, more especially the curious changes in the roots due to the presence of nostoccolonies within their tissues; a further observation of special interest was Reinke's discovery ${ }^{1}$ of two peridermal layers in Cycas circinalis, one derived in the normal manner from the pericambium and the other arising externally at the periphery of the cortex ${ }^{2}$. No observations, however, relating to the abnormal development of secondary wood and bast are recorded by this investigator. In view of the extreme scantiness of our knowledge of anomalous thickening in roots of Cycas, the following observations on the roots (preserved in alcohol) of some seedlings of Cycas Seemanni grown in the Royal Gardens, Kew, from seed obtained from Fiji, may not be without interest. The material of Cycas Seemanni, Al. Braun, which is probably a geographical form of $C$. circinalis, contained five or six good specimens of roots varying in

1 Reinke, Morphologische Abhandlungen, 1873 .

- It may be mentioned in passing that $\mathrm{I}$ hare observed the same condition in the root of Cycas retoluta. 
thickness from about $15-22 \mathrm{~mm}$. in the thickest portions.

The roots investigated were the tap roots of the seedlings; in the lateral roots no anomalous growth whatever was found. The abnormal thickening was confined to a region from $20-40 \mathrm{~mm}$. in length, measured from the junction of the stem with the root.

In order to understand the phenomena which I am about to describe, it will be necessary first to give an account of the structure of the roots in question, before the abnormal development made its appearance. This was easily ascertained by making a series of sections from the younger portion of the root. I found that the very young portions had usually the ordinary diarch arrangement of the bundles; one case of a triarch root was observed. The primary structure need not be described in minute detail, as it agrees in the main with that recorded by Mettenius. The primary groups of the diarch xylem unite to form a median plate, the elements of which become to some extent separated from one another by the greater growth of the conjunctive parenchyma. The primary phloem-groups have the usual position on the right and left of the primary xylem-plate. The normal cambium arises along the inner side of these phloem-groups, and produces in the usual manner two masses of secondary xylem on the side towards the primary plate, while on the outside secondary phloem is produced. Except in one case, to be described later on, the normal cambial layer was not found to become continuous around the ends of the primary xylem. The pericambium was many layers of cells in thickness, as is usual in Gymnosperms, and it is owing to this fact that the abnormality to be presently described is possible. The pericambium is surrounded by a well-marked endodermis of the usual character. This is again surrounded by a wide cortex. The structure of the root at the stage which we are now considering may well be compared with the root of Taxus as figured by Strasburger ${ }^{1}$. It may here be mentioned

1 Das botanische Practicum, p. 201. 
that the roots investigated retained their cortex, even in their oldest portions, only external periderm being formed (see De Bary, 1. c. p. 613). The anomalous development consists essentially in the formation of additional cambial layers external to the normal one; the process as observed appears under two modifications, one of which was only found in a single root, while the other occurred in all the remaining roots examined. The latter will be first described. In this case the abnormal development begins by the formation of cambial divisions in cells of the pericambium lying at a short distance from the ends of the normal cambial layer ${ }^{1}$. Other divisions soon begin both in the cells lying immediately outside the normal phloem, and in those immediately adjacent to the ends of the normal cambium; so that ultimately a complete cambial ring is formed, consisting on its inner side of the original normal cambium, and on its outer side of the more recently formed layer-it will of course be understood that as this process goes on on both sides of the root, two complete rings of cambium are formed. The anomalous portion of each of these rings produces numerous layers of xylem on its outer side and a considerable amount of phloem towards the interior. In this reversed orientation of the products of the first developed anomalous cambium, lies the most characteristic peculiarity of the structures we are considering. As a result of this reversed orientation the tissue lying between the anomalous and the normal cambium becomes compressed (see Figures).

At a somewhat later stage a second process of abnormal development begins; this process, like the one last described, takes its rise from the pericambial tissue. In the cases where the very first origin of this was observed, the development began by divisions in the outermost layer of the pericambiumlying immediately below the endodermis as shown in Fig. 2, and it is thus separated by numerous layers of cells from the

\footnotetext{
1 See description of Figares.
} 
secondary products already considered; these divisions first make their appearance in scattered cells in the layer in question, the exact position of which appears to be indeterminate, with the limitation that the process was never found to begin at the points opposite the primary xylem-groups. The divisions thus started eventually extend to the intervening cells, so as to form a single complete ring of cambium, extending around the vascular cylinder of the root without any interruption, even' opposite the primary groups of xylem. This outer cambial layer thus arises in the position usually occupied by the phellogen of the roots; here, however, its character is that of a true cambium, and it produces numerous xylem-elements on its inner side, and hard and soft bast on its exterior; thus as regards their orientation the tissues produced of this layer are normal. As would be expected from the fleshy character of the root as a whole, the xylem produced does not consist entirely of lignified elements, but includes a number of thin-walled parenchymatous cells scattered among the tracheides.

The general structure of the root at a relatively advanced stage is illustrated by Fig. 3 .

It may be mentioned that in one root belonging to the type first described the original arrangement of the bundle was triarch instead of diarch; here the phenomena of secondary thickening both normal and abnormal went on, mutatis mutandis, precisely in the same way as in the diarch examples, the resulting structure simply showing three inner rings instead of two.

As regards the second form of thickening I have referred to, the primary structure of the root in question was identical with that of the diarch root first described, and the normal secondary thickening also begins in the same way; here however the normal cambium-layer extends around the ends of the primary xylem-plate so as to form a single complete ring $^{1}$. Before this ring is complete the first anomalous cam-

1 As in the case described by Mettenius, 1. c. p. 597. 
bium makes its appearance as above described, but it never becomes continuous with the normal cambium. The orientation of its products is here also reversed as compared with the typical arrangement. The activity of this cambial layer results in the first instance in the production of two isolated bands of secondary tissue lying on either side of the normal vascular mass; subsequently a new series of divisions begins at the outer limit of the pericambium corresponding to those producing the outermost secondary ring in the first type; the products of these divisions resemble those in type $\mathrm{I}$; the outer cambial layer, however, never forms a complete ring round the whole vascular cylinder, but on the other hand becomes continuous on either side with the first anomalous cambial layer (see Fig. 4). If we take only diarch roots into consideration, the differences between the two types may be summed up as follows:-In Type I we get two inner rings of secondary tissue surrounded collectively by a single outer ring; in Type 2 we get a single internal ring flanked on two sides by two anomalous outer rings. As follows from the mode of development described, the outer rings in Type 2 have the opposite arrangement of the xylem and phloem to that in the inner rings of Type $\mathrm{I}^{1}$. It is a point of some interest that all the cambial layers observed appear to continue their activity simultaneously. Judging from the relative thickness of the cell-walls, there is no reason to suppose that the inner cambial layers pass over into permanent tissue when the outer ones begin their activity; how long this simultaneous growth of all the layers may continue could not of course be determined in the material available. As regards the nature of the xylem and phloem-elements derived from the inner and outer abnormal cambium, no important differences were found as compared with the normal secondary tissue.

It is important to mention that the peculiarities of structure described in these roots have no relation to any abnormality

1 The structure of the rings in question may be compared to that of concentric bundles. 
in the stem. In all the seedlings investigated the stem showed simply a normal ring of collateral bundles without any abnormalities of thickening whatever. At the transition from root to stem the anomalous zones of the root abut on the bundles of the stem, in the way indicated in Fig. 3 .

In conclusion, the general results of the investigation may be summed up as follows:-

I. All the anomalous thickening observed proceeds from cells of the many-layered pericambium.

2. The first anomalous cambium arises in the inner portions of this zone.

3. The second anomalous development starts from the extreme outside of the pericambium.

4. The orientation of the inner anomalous tissues is reversed, the phloem lying towards the centre, the xylem towards the periphery of the root.

5. In the outer anomalous region the orientation is normal.

That further processes of abnormal development may occur in the older root is extremely probable, but this can only be determined by the examination of more advanced specimens than those at my disposal.

\section{EXPLANATION OF FIGURES IN PLATE VI.}

Fig. I. Transverse section of a root of type 1 , showing a portion of the vascular cylinder only. $p r . x y$. primary rylem plate. $p r . p h$. compressed remains of primary phloem. $*$. $c b$. normal cambium. a. $c b .1$ first abnormal cambinm, its products have reversed orientation. $a$. $c b$., second abnormal cambinm. $z$. approrimate starting points for the development of the first abnormal cambiom. The cells shaded black contain tannin. ( $x$ aboat 45 .)

Fig. 2. Portion of a transverse section of a younger root of type 1 , showing the origin of the second abnormat cambium. The first abnormal cambinm has already produced numerous permanent elements. $c$. endodermis, $a$. $c b$, second abnormal cambium. $t$. tracheid already derived from it. $a . c b_{n}$ furst abnormal cambium. ( $x \mathrm{I}_{4}$ o.)

Fig. 3. A. Longitudinal section of the junction between stem and root in type $I$. B. Transverse section through the root of the same. c. o.r. common outer ring. 
i. r. inner rings, in each of which the half towards the centre of the root has been derived from the normal, the half towards the periphery from the first abnormal cambium. ex. pd. external periderm. st. $b$ normal ring of bundles in the stem. $\left(\begin{array}{ll}x & 2 .)\end{array}\right.$

Fig. 4 Transverse section of a root of type 2. n. r. normal ring. o.r. abnormal outer rings. c. endodermis. $p$. pericambium. ex. pal. external periderm. $(\times 4$.

In Figs. 3 and 4 , the xylem is coloured yellow, the phloem blue, and the periderm brown. 


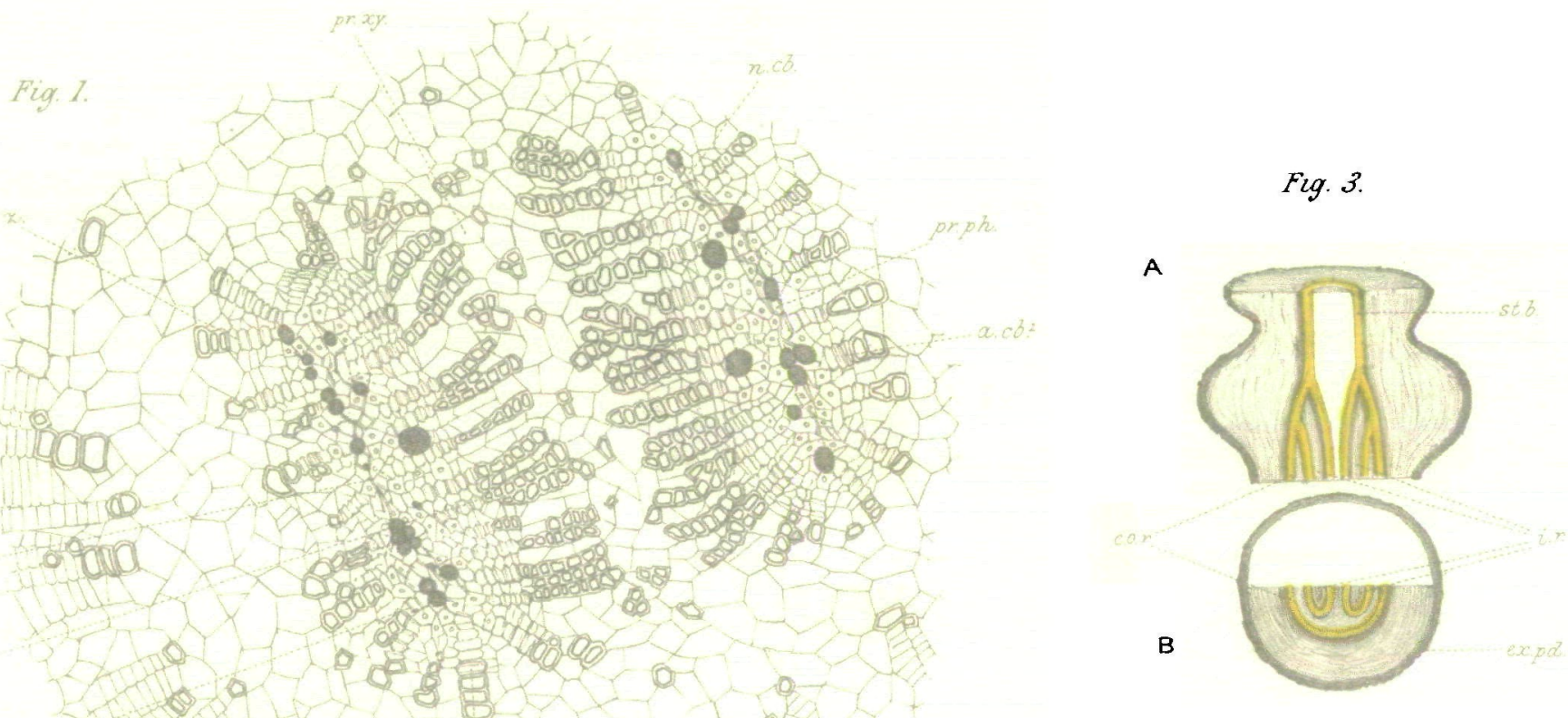

\section{8 .}

Q a ns

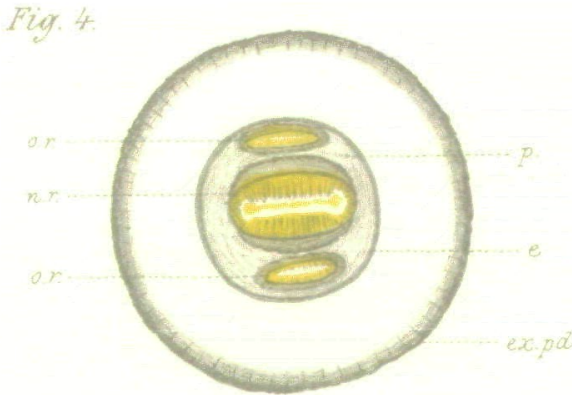

Gre $\delta 8$ del

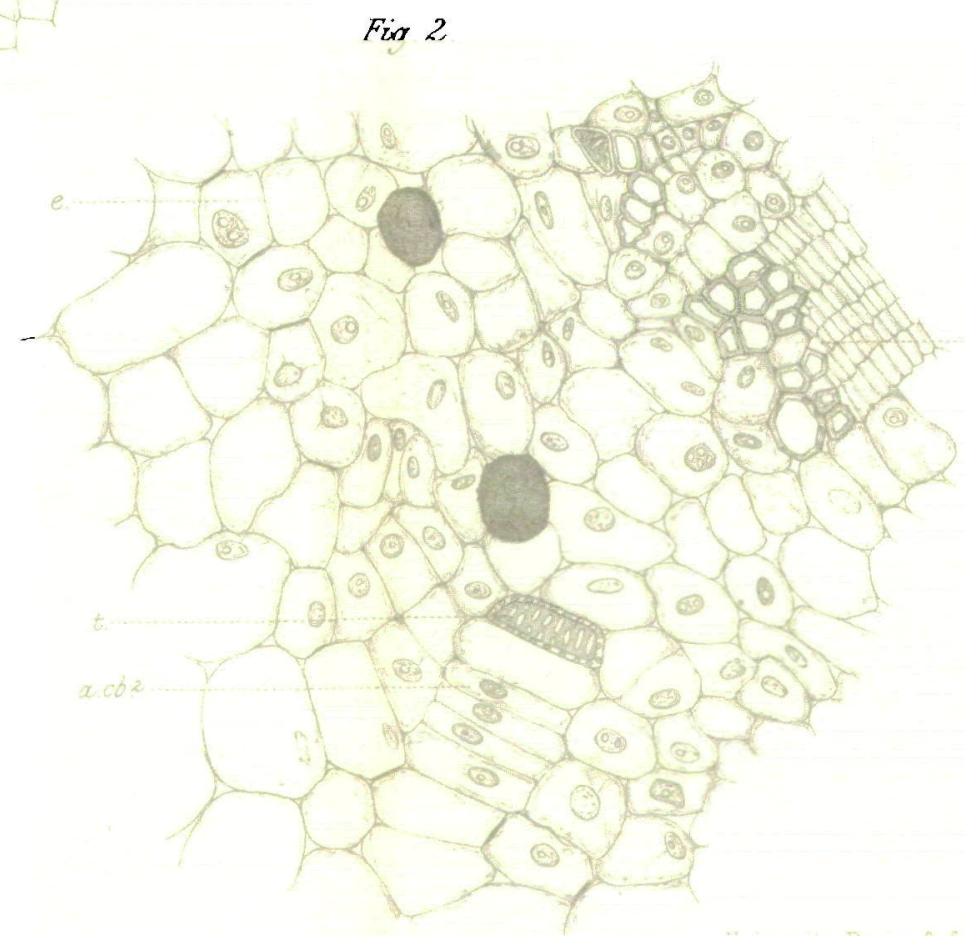


1 